\title{
Acute Encephalitis Syndrome in India: The Changing Scenario
}

\author{
Sourish Ghosh Anirban Basu \\ National Brain Research Centre, Manesar, Haryana, India
}

Acute encephalitis syndrome (AES) is characterized by an acute onset of fever and clinical neurological manifestation that includes mental confusion, disorientation, delirium, or coma [1]. Viruses have been mainly attributed to be the cause of AES in India although other sources such as bacteria, fungus, parasites, spirochetes, chemical, and toxins have been reported over the past few decades [1]. Apart from viral encephalitis, severe form of leptospirosis and toxoplasmosis can cause AES. The causative agent of AES varies with season and geographical location, and predominantly affects population below 15 years [1]. Keeping in mind the wide range of causal agents and the rapid rate of neurological impairment due to pathogenesis, clinicians face the challenge of a small window period between diagnosis and treatment. The present report is based on results obtained after reviewing various surveillance and outbreak investigations illustrating how the perspective of AES has changed in India over the years.

The history of AES in India has paralleled with that of the Japanese encephalitis virus (JEV) since the first report in 1955 from Vellore, Tamil Nadu. The first outbreak of JEV was reported in Bankura district, West Bengal in 1973. Thereafter, sporadic cases of AES and outbreaks have been the leading cause of premature deaths due to the disease in India. Based on various surveillance reports and outbreak investigations, Joshi et al. [1] classified the history of AES in India into 3 phases: (a) period before 1975 when a few cases with JE aetiology were identified; (b) between 1975 and 1999 when more JEV cases were reported with frequent outbreaks that resulted in the development of JE endemic regions near the Gangetic plains and in parts of Deccan and Tamil Nadu; (c) between 2000 and 2010, a dramatic change was observed in the AES scenario, which saw the rise in non-JE outbreaks mostly caused by viruses such as Chandipura virus (CHPV), Nipah virus (NiV), and other enteroviruses (fig. 1).

In recent times, that is, after 2012, AES cases in India have shifted towards the JE aetiology. Based on the reports, Indian states of Uttar Pradesh (UP), Bihar, Assam, West Bengal, and Tamil Nadu were identified as JE endemic zones. In the year 2013, starting from the monsoon months till the end of November, 2,205 people were reported to be affected by JE, and the death toll due to JE rose up to 590 (Indian Express, November 26, 2013). Many cases of AES were reported in 2014 from the states of UP (3,329 cases, 627 deaths), Assam (2,194 cases, 360 deaths), West Bengal (2,381 cases, 169 deaths), and Bihar (1,385 cases, 355 deaths) (Indian Express, September 22, 2015). JE was the major cause of these deaths, albeit virologists identified another causal agent in the form of 'toxin-mediated illness'. Investigators hypothesized the causal agent as a toxin prevalent in the litchi fruit (Indian Express, October 14, 2014). In these cases, although encephalitis was not confirmed, pathogenesis lead to encephalopathy with hypoglycaemia. Sixty-three percent of 390 patients suffered from hypoglycaemia with low blood glucose level of $70 \mathrm{mg} / \mathrm{dl}$, and it was observed that only

\section{KARGER}

E-Mail karger@karger.com

www.karger.com/aon
(C) 2016 S. Karger AG, Basel

0972-7531/16/0233-0131\$39.50/0
Anirban Basu

National Brain Research Centre

Manesar, Haryana 122051 (India)

E-Mail anirban@nbrc.ac.in 
Fig. 1. Endemic regions of various viruses reported to cause AES in India. JEV has its endemic zones running along the Gangetic plane including states of UP (east), Bihar, West Bengal and Assam, and parts of Tamil Nadu. CHPV that hit the states of Maharashtra (in Nagpur district) and eastern part of Gujarat in 2003 has extended its influence in the states of Andhra Pradesh. $\mathrm{NiV}$ hit the south-east Asian countries, mainly Bangladesh. It had its first outbreak in Siliguri, West Bengal in 2001. NiV again caused an outbreak in Nadia district of West Bengal in 2007. Enterovirus outbreak was first reported from Gorakhpur, UP in 2006. Litchi virus was the latest virus in the list that caused AES in Muzzafarpur, Bihar and Malda, West Bengal from 2013 to 2014.

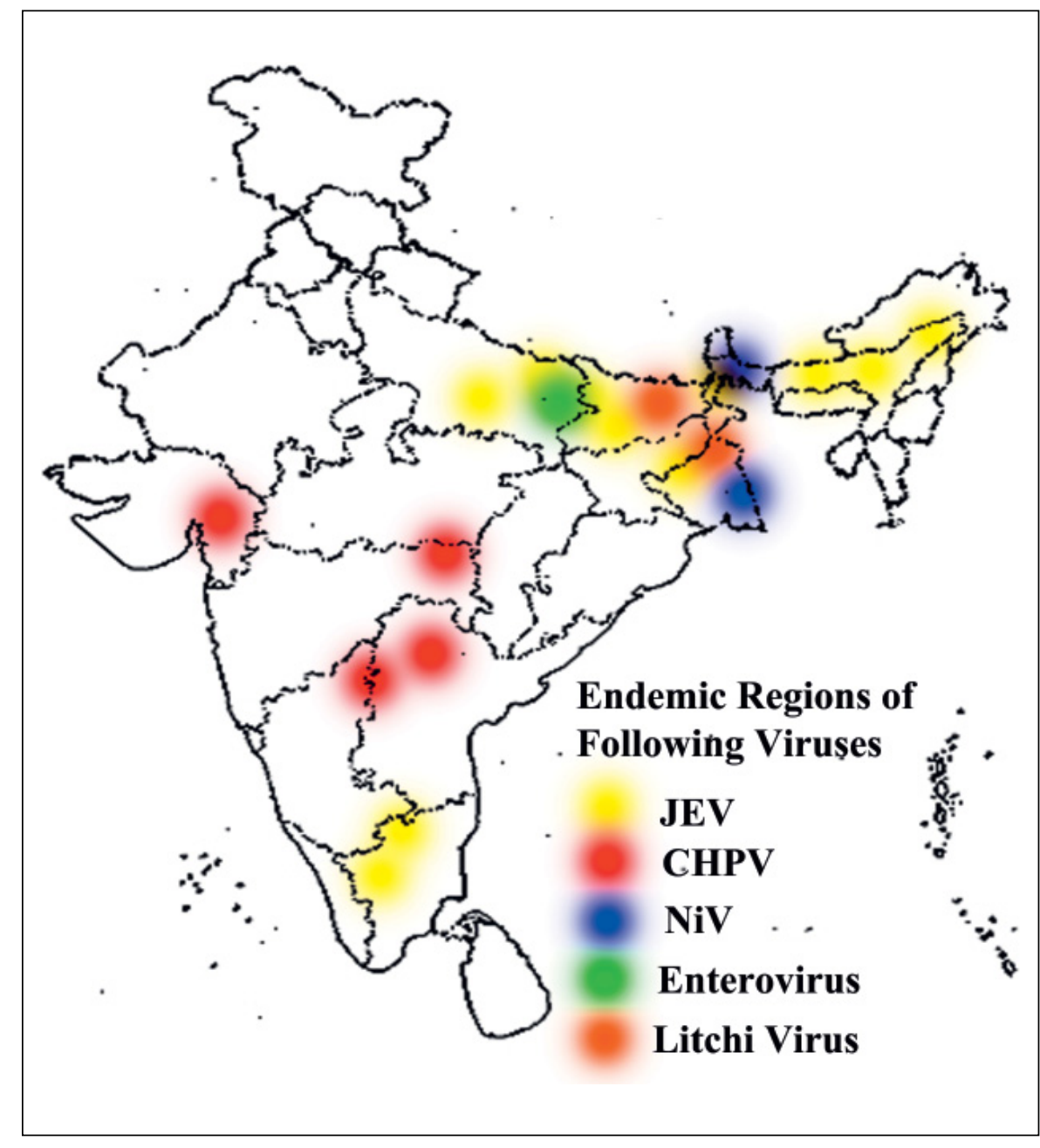

treatment for hypoglycaemia reduced the number of deaths from $44 \%$ in 2013 to $26 \%$ in 2014 . The toxin was identified as methylene cyclopropyl glycine and was found to rise in litchi seed. Later, though not confirmed, the rise in the toxin in litchi seeds was implied to the use of alpha cypermethrin above the minimum safety levels (Indian Express, July 23, 2014).

Several government initiatives have been undertaken to educate and improve the hygiene of people living in the JE endemic zones. Government and non-government organizations have been instrumental in providing proper nutrition to the AES-affected population as most of the affected people belong to the lower economic strata of the society. There have been initiatives to help the people residing in the endemic zones for alternative professions such as giving up pig-rearing since pigs are the primary host for JE viruses. Special schools have been set up to help children challenged by clinical sequelae of JE infec- tion (Indian Express, October 19, 2012). Vero cell-derived purified inactivated JE vaccine-JENVAC, was the first vaccine in India that received manufacturing and marketing approvals from the Drug Controller General of India. The vaccine was an outcome of public-private partnership mode between the Indian Council of Medical Research and Bharat Biotech (The Hindu, October 4, 2013). Minocycline, a second generation tetracycline was reported from our laboratory to be protective against JE in the animal model [2]. Based on a pre-clinical study, a phase II clinical trial has been completed at the CSM Medical University (King George Medical College). The trial report showed better outcomes with minocycline, especially in those patients who survived the initial day in hospital [3], although the exact mechanism of action has remained enigmatic.

AES was coined way back in 2008 by the World Health Organization to streamline the surveillance and research 
of AES in India. Over the years, the scenario of AES in India has improved significantly in terms of research and health care facilities. Albeit the development of vaccine against JEV and minocycline under the clinical trials, AES cases in India has not restricted itself to the JE aetiology. This is the biggest challenge clinicians in the field are fac- ing. As mentioned previously, viruses such as $\mathrm{CHPV}, \mathrm{NiV}$ often emerge in the scenario, leading to massive outbreaks. Development of pan-anti-viral drugs is the order of the day. Pan-anti-viral drugs are not only effective across a wide range of viruses, but they also reduce the time lost between the identification of the virus and treatment.

\section{References}

1 Joshi R, Kalantri SP, Reingold A, Colford JM Jr: Changing landscape of acute encephalitis syndrome in India: a systematic review. Natl Med J India 2012;25:212-220.
2 Mishra MK, Basu A: Minocycline neuroprotects, reduces microglial activation, inhibits caspase 3 induction, and viral replication following Japanese encephalitis. J Neurochem 2008;105:1582-1595
3 Kumar R, Basu A, Sinha S, Das M, Tripathi P, Jain A, et al: Role of oral Minocycline in acute encephalitis syndrome in India - a randomized controlled trial. BMC Infect Dis 2016;16:67. 